\title{
Rapid Airfoil Design for Uncooled High Pressure Turbine
}

\section{Blades}

\author{
Niloofar Moradi ${ }^{1}$, Edward Vlasic ${ }^{1}$, Hany Moustapha ${ }^{2}$ and Francois Garnier ${ }^{2}$ \\ 1. Turbine Design Department, Pratt and Whitney Canada (P\&WC), Longueuil (Québec), J4G1A1, Canada \\ 2. Mechanical Engineering Department, Engineering School (ETS), University of Quebec, Montréal (Québec), H3C1K3, Canada
}

\begin{abstract}
The aero-engine design process is highly iterative, multidisciplinary in nature and complex. The success of any engine design depends on best exploiting and considering the interactions among the numerous traditional engineering disciplines such as aerodynamics and structures. More emphasis has been placed lately on system integration, cross disciplines leveraging of tools and multi-disciplinary-optimization at the preliminary design phase. This paper investigates the automation of the airfoil generation process, referred to as Rapid Airfoil 3D (RAF-3D), for uncooled high pressure turbine blades at the preliminary design phase. This approach uses the TAML (Turbine Aero Mean Line) program in parallel with a database of previously designed P\&WC airfoils, in-house design rules and best practices to define a pre-detailed airfoil shape which can be fed back to other analytical groups for pre-detail analyses, such as for structural integrity and vibrations. Resulting airfoil shapes have been aerodynamically validated using an in-house three dimensional Reynolds averaged Navier-Stokes code. RAF-3D will shorten the turnaround time for Pratt \& Whitney turbine aerodynamics group to provide a preliminary 3D airfoil shape to turbine structures group by up to a factor of ten. Additionally, the preliminary assessments of stress and vibration specialists will be more accurate as their assessments will be based on an airfoil that has had inputs from all functional groups even though it is "first pass" design.
\end{abstract}

Key words: Optimization, turbine, blade, preliminary design, CFD (Computational Fluid Dynamics).

\section{Nomenclature}

$\alpha \quad$ Flow Angle (1 inlet; 2 exits)

$\beta \quad$ Metal Angle (1 inlet; 2 exits)

$\tau \quad$ Airfoil Cross Sectional Throat Opening

$\mathrm{B}_{\mathrm{m}} \quad$ Meridional Chord

$\mathrm{B}_{\mathrm{x}} \quad$ Axial Chord

BP Best Practices

CAD Computer-Aided Design

CG Center of Gravity

GUI Graphical User Interface

HPT High Pressure Turbine

LED Leading Edge Diameter

LEMA Leading Edge Metal Angle

LEWA Leading Edge Wedge Angle

PMDO Preliminary Multi-Disciplinary Optimization

P\&WC Pratt \& Whitney Canada

$\mathrm{R} \quad$ Radius

RAF-3D Rapid Airfoil tridimensional (3D)

RANS Reynolds-Averaged Navier-Stokes

TAML Turbine Aero Meanline

Corresponding author: Francois Garnier, Ph.D., professor, research fields: CFD, aircraft propulsion.

\author{
TEMA Trailing Edge Metal Angle \\ TET Trailing Edge Thickness \\ TEWA Trailing Edge Wedge Angle \\ UT Uncovered Turning
}

\section{Introduction}

For over 60 years, gas turbine technology has continuously evolved and advanced. Different technologies have been introduced to increase the overall efficiency of gas turbines, which in turn reduces fuel-consumption. This has become a very attractive subject due to the increasing cost of fuel. The increase in greenhouse gas pollution caused by gas turbines is another driver for the vast amount of research done by several industry leaders. This has strongly driven the development of gas turbine engines with ever improving efficiencies. The turbine, being at the heart of the aircraft engine, is indeed an area that could be improved given an extended design schedule and infinite computational power. Furthermore, the 
evolution of the gas turbine engine industry is largely affected by the engine design process, which explains why many industry leaders have been focusing their attention on improving the sub-processes in the design environment and essentially the overall design process which includes many interactions among different engineering disciplines (for example, aerodynamics, structures and dynamics) and life cycle disciplines such as manufacturability and cost [1]. The concept design stage is an extremely important step while aiming for this effort because "the best engineering effort cannot totally right a poor concept selection" [2]. This is why there has been great interest in the subject of PMDO (Preliminary Multi-Disciplinary Optimization) in aerospace. Airfoil Cloning is a BMW-Rolls Royce in house code, where the knowledge from previous designs is carried forward to a new upcoming design through the use of a database of all previously designed airfoils in a unique parameterized manner, allowing the user to load a baseline airfoil and update the meanline aero parameters (such as metal angles) through a GUI (Graphical User Interface) [3]. Anders, et al. [4] have used the in house code called AutoBlading, which transforms existing blades to one common representation in order to detect any existing correlations between parameters. This approach was used to come up with a standardized design approach for several compressors such as Trent500 and Trent800 High-Pressure compressor [4]. P\&WC (Pratt and Whitney Canada), aims to leverage on the great potential of a PMDO project in order to greatly reduce the design time and achieve better over-all engine performance [5]. In addition the overall risk to an engine program will be greatly reduced because the need, for example, to "cut-back" a portion of the blade tip to reduce dynamic stresses in development, will most likely, be eliminated.

RAF-3D (Rapid Airfoil 3D) is an important part of the P\&WC-École de Technologie Supérieure (Quebec University) joint PMDO program aiming to automate and improve the preliminary airfoil design process, which is a manual and very tedious process at the moment. This particular work aims to generate a first pass 3D airfoil that meets the preliminary cross-sectional area requirements imposed by the structures calculation. The current focus of RAF-3D is the uncooled high pressure turbine blade due to its complex design requirements, and the aim is to later integrate RAF-3D into the design of other airfoil types. A great deal of research has been done in the field of turbine design process improvement, not the least of which are optimization, tool improvement and process automation. It has to be emphasized here that aerodynamic design of an airfoil is affected by many other aspects such as stress and dynamics. The whole design process is a series of iterations during which all analysts must account for conflicting requirements. Preliminary airfoil design at P\&WC starts at the meanline level where the velocity triangles are predicted in a free vortex environment with the corner points of each airfoil basically defining the gaspath. At this stage, if the design forecast is promising, the aerodynamicist will take a "baseline or reference" 3D airfoil and manually update all the parameters at the mid-section, taken from the meanline. Considering a typical three-section design of a high pressure turbine blade (which will be the focus of this paper), the aerodynamicist must then predict the parameters for hub and tip sections of the airfoil using different design rules and knowledge from previous turbine designs. Turbine aerodynamics is then provided with a cross-sectional area distribution from hub to tip that meets structural requirements. A cycle zero airfoil will then be produced based on modified reference sections that each meets the cross-sectional area requirement.

Therefore, the objective of this work is to accelerate the concept design cycle of an airfoil, without losing any quality of the manual process. In order to achieve this objective the following is performed. First, a set of correlations, which were derived from data collected from previously designed airfoils, are developed. Second, a parametric 3D CAD model is 
created from which a 3D airfoil shape is then defined. Third, the entire airfoil generation process (RAF-3D) is automated. The process will be validated by recreating three existing airfoils by using RAF-3D process. Each airfoil's performance is then analyzed and compared to its reference using CFD (Computational Fluid Dynamics).

\section{RAF 3D Approach}

RAF-3D generates a preliminary three-dimensional airfoil consisting of three design sections (hub, mid and tip) that respect all aerodynamic design considerations and the cross sectional area distribution required to meet the target stress field. RAF-3D has five main inputs:

(1) TAML (Turbine Aero Mean Line);

(2) A database of $\mathrm{P} \& \mathrm{WC}$ aerodynamic parameters pertaining to previously designed airfoils (and in the specific case of this paper, uncooled high pressure turbine blades);

(3) An existing airfoil as baseline;

(4) Design best practices;

(5) Airfoil area distribution requirements.

TAML inputs and calculations govern some of the aerodynamic parameters at mid-section. The 1D meanline calculations are some of the most important inputs for RAF-3D.

In early stages of this work, a database of all design parameters available in the existing P\&WC meanline and/or design reports dating from 1985 to 2011 was constructed. The intent was to observe any existing trends and predict some of the more critical mid-section parameters, such as throat opening, and compare with those predicted in the meanline calculations. This database is also to be used to create the mid to hub and tip correlations that are used for predicting the hub and tip sections' parameters.

An existing "baseline" airfoil is used to predict the mid-to-hub and mid-to-tip ratios for parameters, such as meridional chord. In order to choose the appropriate airfoil, the engine type (turboshaft, turboprop, etc.), size, altitude, rim speeds and temperatures must be taken into account as these parameters will translate to stress requirements of the blade.

In-house aero design best practices are another input for RAF-3D, where parameters such as UT (Uncovered Turning) (Fig. 1) are set to values based on these guidelines.

Once the parameters for three design sections are read, calculated and/or predicted, a fully parameterized 3D CAD model (constructed from the three design sections) is updated to generate the first pass 3D airfoil shape. A careful study of geometrical airfoil parameters was crucial for pinpointing the minimum number of parameters necessary at each airfoil section for defining a pre-detail three-dimensional airfoil.

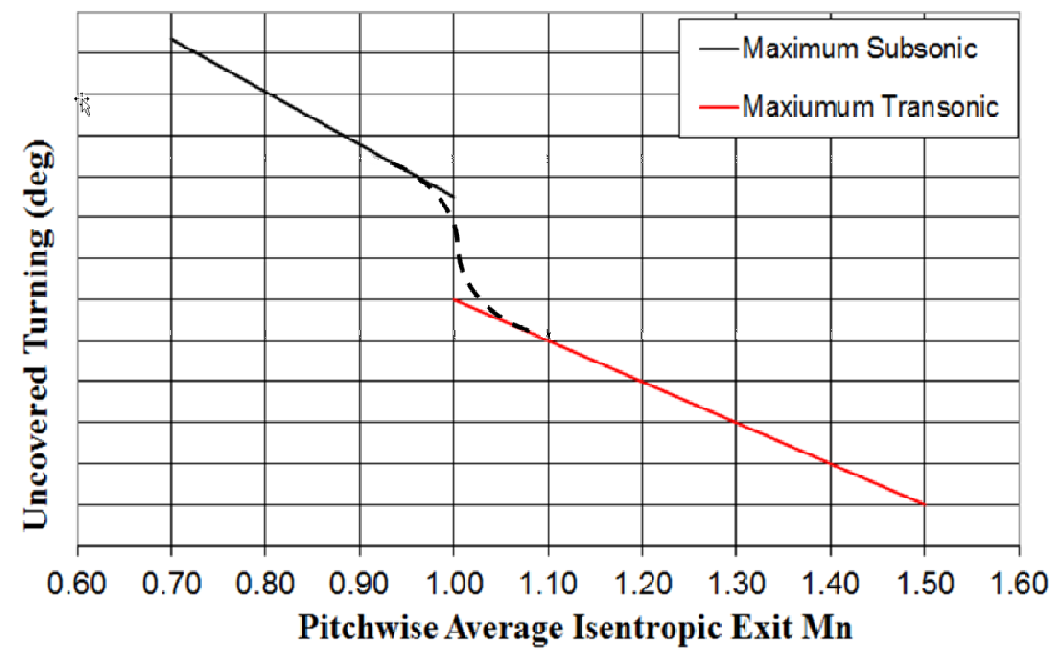

Fig. 1 Uncovered turning criterion. 
The minimum parameters necessary for defining each airfoil section in RAF-3D are found to be as follows:

- Number of airfoils;

- Design section radii (hub, mean and tip);

- Cone angle;

- Meridional chord $\left(\mathrm{B}_{\mathrm{m}}\right)$;

- Axial chord $\left(\mathrm{B}_{\mathrm{x}}\right)$;

- LED (Leading Edge Diameter);

- TET (Trailing Edge Thickness);

- LEMA (Leading Edge Metal Angle) referred to as "inlet blade angle" in Fig. 2;

- TEMA (Trailing Edge Metal Angle) referred to as "exit blade angle" in Fig. 2;

- LEWA (Leading Edge Wedge Angle);

- TEWA (Trailing Edge Wedge Angle);

- Stagger angle;

- Throat opening;

- UT.

A sketch defining the following parameters: leading and TEMAs, LED, TET and stagger angle is shown in Fig. 2.

Fig. 3 illustrates the following parameters: design section radii (hub, mean and tip), cone angle, meridional and axial chord $\left(\mathrm{B}_{\mathrm{m}} / \mathrm{B}_{\mathrm{x}}\right)$.
Fig. 4 illustrates the following parameters: leading and TEWAs, throat opening and UT.

A two-dimensional airfoil section CAD model was developed in order to validate whether the parameters noted above were indeed the minimum for defining an airfoil section, while providing flexibility for achieving target areas. The parameters were shown to be sufficient.

An optimization loop will then be used to match the area requirements, where target cross-sectional area distribution from hub to tip is the objective function and certain parameters, such as LEWA and LED, which are varied to match the design section area to that of the target. Once the area requirements have been met, the resulting 3D airfoil will be evaluated to ensure it meets the stress and dynamics requirements.

In order to best summarize RAF-3D process of generating a 3D airfoil shape in the pre-detail environment, the process has been broken down to two steps: mid-section parameter prediction and hub and tip sections parameter extrapolation. Before exploring details of these steps however, all assumptions must be listed and parameters are assumed constant for all sections as described below:

\begin{tabular}{ll} 
Leading Edge & (L.E.) \\
\hline Trailing Edge & $($ T.E.) \\
Pressure Surface & $(P S)$ \\
Suction Surface & (SS) \\
Chord & $(B)$ \\
Axial Chord & $(B x)$ \\
Stagger Angle & $(\gamma)$ \\
Pitch or Spacing & $(S)$ \\
\hline Height or Span & $(h)$ \\
\hline Throat & $(O)$ \\
& \\
Blade or Metal Angles & $\left(\beta_{1}, \beta_{2}\right)$ \\
\hline Flow or Gas Angles & $\left(a_{1}, a_{2}\right)$ \\
\hline Incidence Angle & $1=a_{1}=\beta_{1}$ \\
\hline Deviation Angle & $\delta=a_{2}-\beta_{2}$ \\
\hline Camber Angle & $\theta=\beta_{1}-\beta_{2}$ \\
Flow Defection & $\varepsilon=a_{1}=a_{2}$ \\
Aspect Ratio & $A R=\hbar / c$ \\
\hline Solidity & $\sigma=C / S$ \\
Pitch Chord Ratio & $S / C$
\end{tabular}

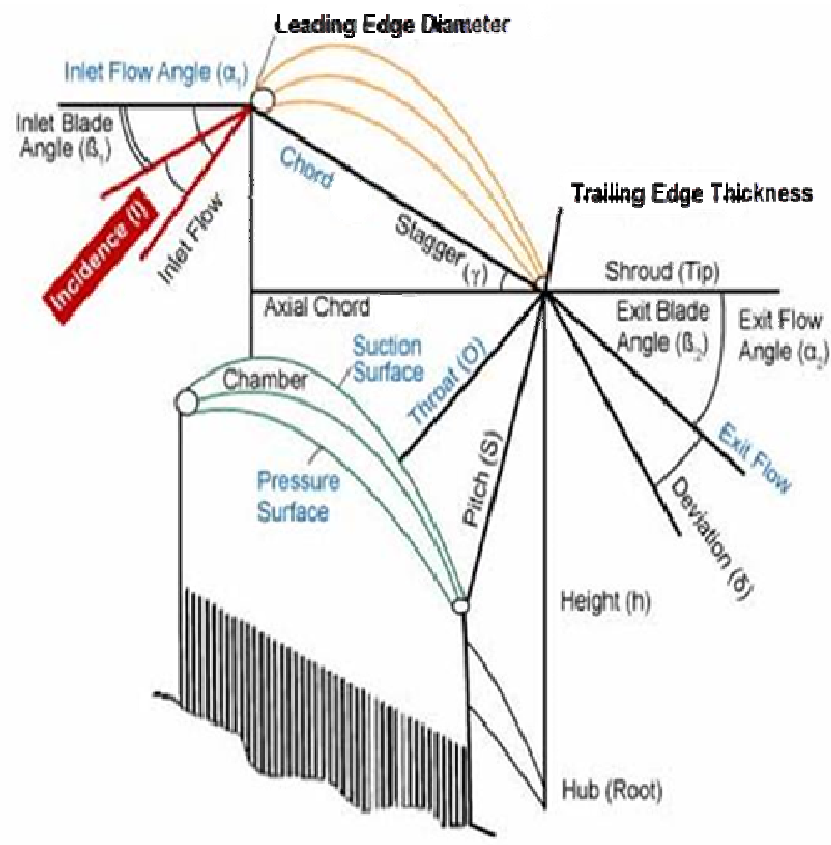

Fig. 2 Airfoil geometry terminology [6]. 


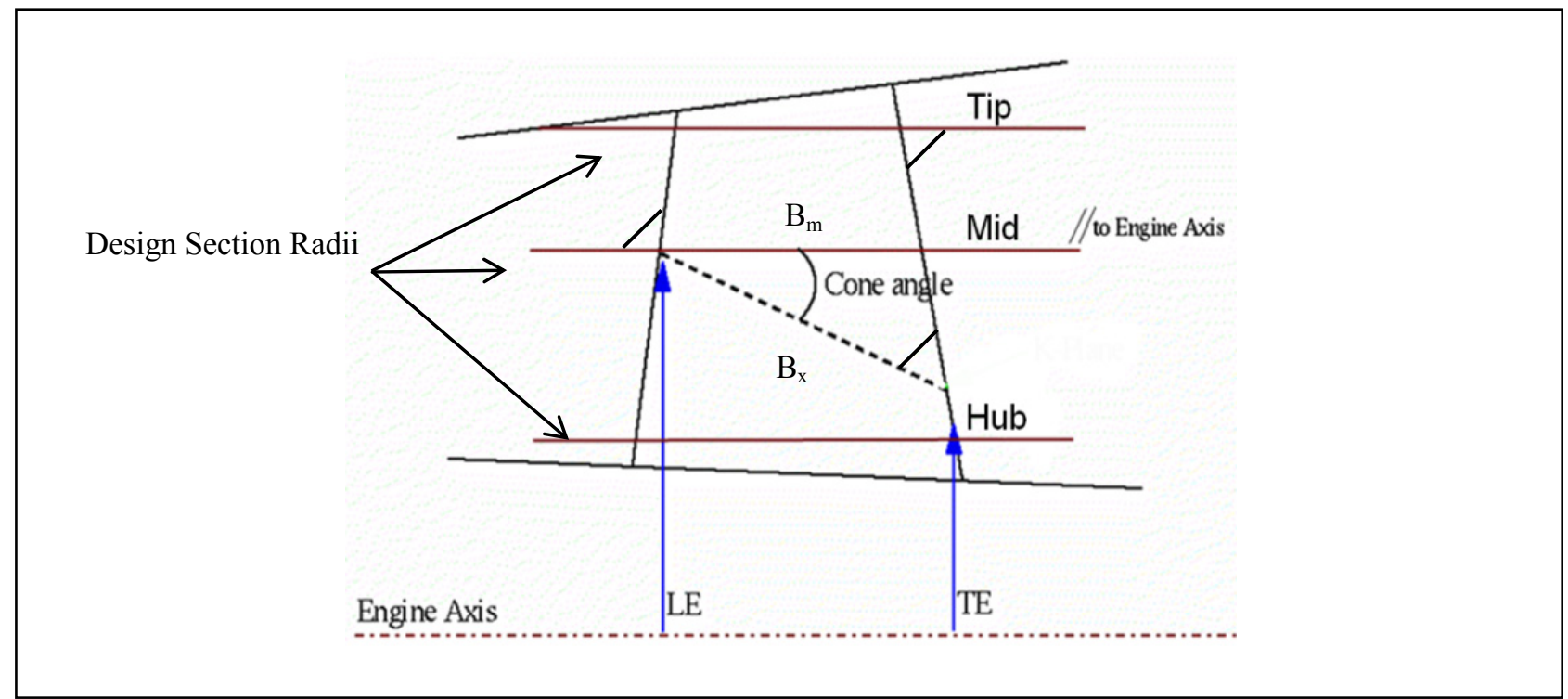

Fig. 3 Cone angle definition.

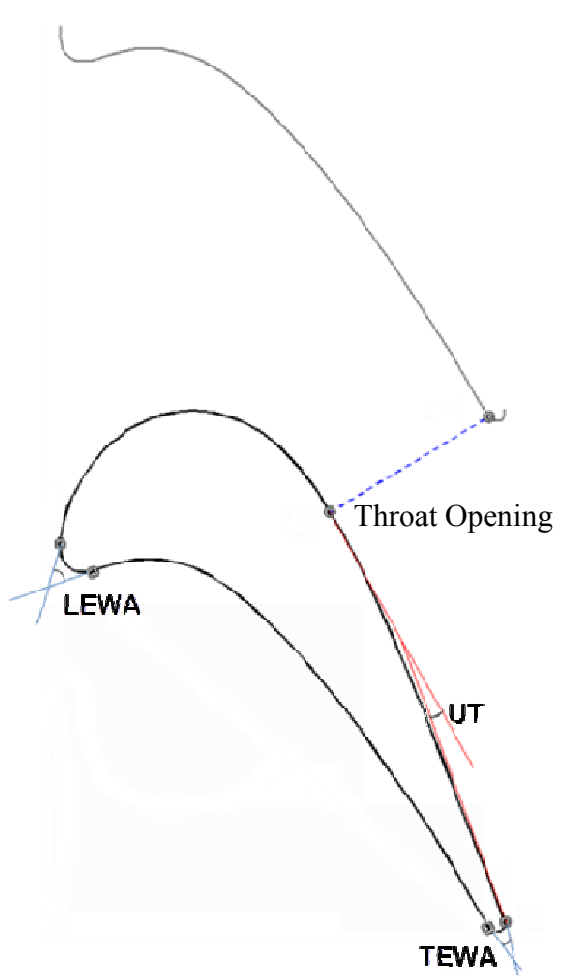

Fig. 4 UT, LEWA and TEWA definition.

(1) All sections are designed with a zero cone-angle. This is an acceptable assumption as the gaspath of an uncooled HP turbine blade normally has a small flare at the hub and no flare at the tip. Consequently, designing with zero cone-angle throughout is desirable. Even if the gaspath is flared at the hub, to design with a cone angle or not is up to the aerodynamicist.

(2) For all sections, incidence and deviation angles are assumed constant as per P\&WC in-house design best practices for uncooled HP turbine blades.

(3) As per data collected from previously designed airfoils, TEWA of uncooled HP turbine blade is assumed to be constant from hub to tip.

(4) LEWA for each design section is set equal to that of the existing "baseline" airfoil. This is used just as a first guess, as it (among a few other parameters) may be varied to achieve the area requirements.

Table 1 is a summary of the parameters used to parameterize the airfoil section CAD model and a brief description of the source of the values assigned to each parameter. Following sections (2.1 and 2.2) provide a detailed description for this table.

\subsection{Mid-section Parameter Prediction}

TAML is one of the main sources of information for RAF-3D. It contains inputs for each section and global parameters such as airfoil count and gaspath corner points. Focusing the attention on mid-section parameter prediction, apart from the parameters that are assumed constant (see previous section), the following parameters at mid-section are read from TAML inputs (some already reflecting manufacturing 
Table 1 RAF-3D concept airfoil parameter origin.

\begin{tabular}{lll}
\hline & \multicolumn{2}{c}{ Concept airfoil parameters' origin } \\
\hline Parameters & MID & HUB \& Tip \\
\hline Airfoil count & TAML & TAML \\
Inlet radius & TAML & TAML \\
Exit radius & TAML & TAML \\
Design radius & Calculation & Calculation \\
Cone angle & Constant $=0$ & Constant $=0$ \\
Meridional chord & TAML & Baseline design ratio \\
LED & TAML & Baseline design ratio \\
TET & TAML & Baseline design ratio \\
Stagger angle & Correlation & Correlation (w.r.t mid) \\
LEMA & Calculation & Calculation \\
TEMA & Calculation & Calculation \\
Incidence & BP & BP \\
Deviation & BP & BP \\
Inlet flow angle & TAML & Correlation (w.r.t mid) \\
Exit flow angle & TAML & Correlation (w.r.t mid) \\
Throat opening & Correlation & Correlation (w.r.t mid) \\
UT & BP & BP \\
LEWA & 1 st guess baseline & 1st guess baseline \\
TEWA & BP & BP \\
\hline & & \\
\hline
\end{tabular}

and cooling requirements): mid-section radii, axial chord $\left(\mathrm{B}_{\mathrm{x}}\right)$, LED, TET, and leading and trailing edge gas angles Meridional chord $\left(\mathrm{B}_{\mathrm{m}}\right)$ is calculated using trigonometry:

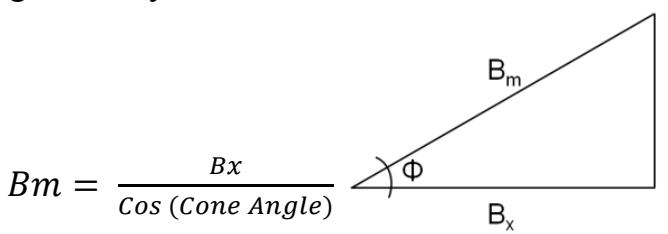

As cone angle is assumed to be zero for all sections, $B_{m}$ at mid-section is equal to $B_{x}$ at that section (obtained from TAML).

LEMA and TEMA can also be calculated as follows:

$$
\text { LEMA @MID }
$$

$=[$ Inlet Flow Angle (from TAML)@ MID $]-[$ incidence $]$

Similarly,

$$
\begin{aligned}
\mathrm{TEMA}_{@ \mathrm{MID}}= & {[\text { Exit Flow Angle (from TAML) } @ \text { MID }] } \\
& +[\text { Deviation }]
\end{aligned}
$$

For the mid-section parameters listed thus far,
TAML has been the primary source of information. There are some parameters for airfoil shape definition for which there is a need for a database of P\&WC aerodynamic parameters pertaining to previously designed airfoils. These are throat opening, stagger angle, UT, leading and TEWAs.

RAF-3D has improved the accuracy of mid-section throat estimation. Before describing the details on how this was achieved, the current TAML throat opening approximation $\tau$ for mid-section of the airfoil is described. An in-house approximation for throat opening was developed using data collected from the designs to date. This approximation (a modified Gress equation) is listed here:

$$
\begin{gathered}
\frac{\tau}{\mathrm{TET}}=\frac{1}{K_{1}} *\left(2 * \pi * \frac{\mathrm{R}}{\mathrm{n} * \mathrm{TET}}-K_{2}\right) * \\
\cos \left(\alpha_{\text {out }}\right)
\end{gathered}
$$

where:

$\mathrm{R}=$ Radius;

$\mathrm{n}=$ Number of airfoils;

TET $=$ Trailing edge thickness; 
$\alpha_{\text {out }}=$ Exit flow angle;

$\mathrm{K}_{1}=0.92$;

$\mathrm{K}_{2}=2.50$.

Data collected on throat opening values dating back to the $1980 \mathrm{~s}$ were plotted against this improved approximation (Eq. (4)). By performing linear regression through the data a better slope is achieved, however an offset was noticed, in which throat area approximated in TAML appeared to be more open. Observing this trend, RAF-3D modified this approximation by applying an offset value to the original equation as shown in Fig. 5.

In order to evaluate the accuracy of this approach, five test cases from previous high pressure turbine blade designs were carried out. In these cases throat openings were estimated using RAF-3D. These values were then compared to the final design values at the mid and a percentage error was calculated. The largest error was $10 \%$. A modest restagger of the blade, to achieve the ultimate target throat opening, is estimated not to adversely affect the airfoil shape enough to invalidate either the aerodynamics acceptability or structural and stress conclusions at the preliminary design phase.

Stagger angle is another important parameter needed during the airfoil design process. For a turbine blade in a gas turbine, the camber will dictate, to some degree, the optimum stagger of the airfoil, because of the need to optimize curvatures and throat. Stagger angle could also be used for decreasing or increasing the cross sectional area to achieve the target area distribution. This parameter is not well approximated in the free-vortex meanline calculations. In an attempt to improve the accuracy of stagger prediction at mid-section, the existing Kacker and Okapuu's [7] correlation between stagger and flow angle has been utilized and updated with the latest P\&WC designed airfoils. In the original correlation, for given values of inlet and exit flow angles, the stagger angle could be found. RAF-3D however has explored the possibility of correlating inlet flow angle to stagger angle for specific ranges of exit flow angle. This newly generated set of curves was used to estimate the stagger angles of five test cases which were then compared to the actual final design stagger angles. Even though the approach proposed here did not appear to have increased the accuracy of the existing Kacker and Okapuu's correlation, it is still a better option as it includes the latest P\&WC designs. Figs. $6 \mathrm{a}$ and $6 \mathrm{~b}$ are representations of Kacker and Okapuu's [7] and RAF-3D stagger prediction.

UT is the last parameter necessary for defining an airfoil section in RAF-3D. This parameter is not estimated in the meanline. Therefore, industrial

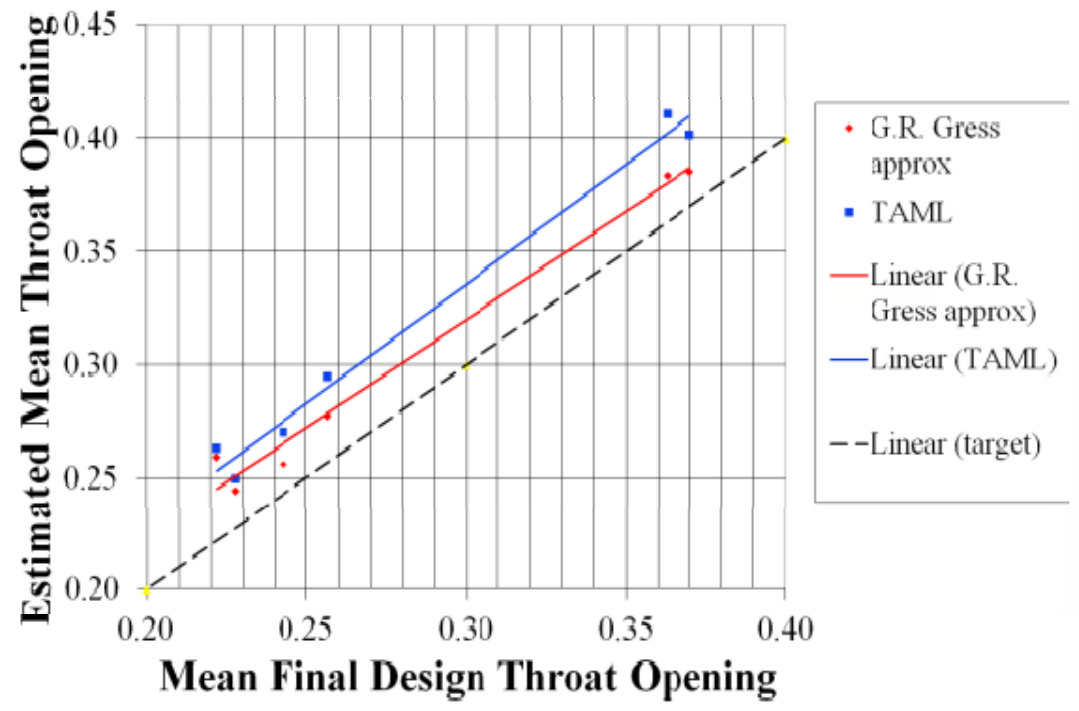

Fig. 5 In-house mid-section throat approximation. 


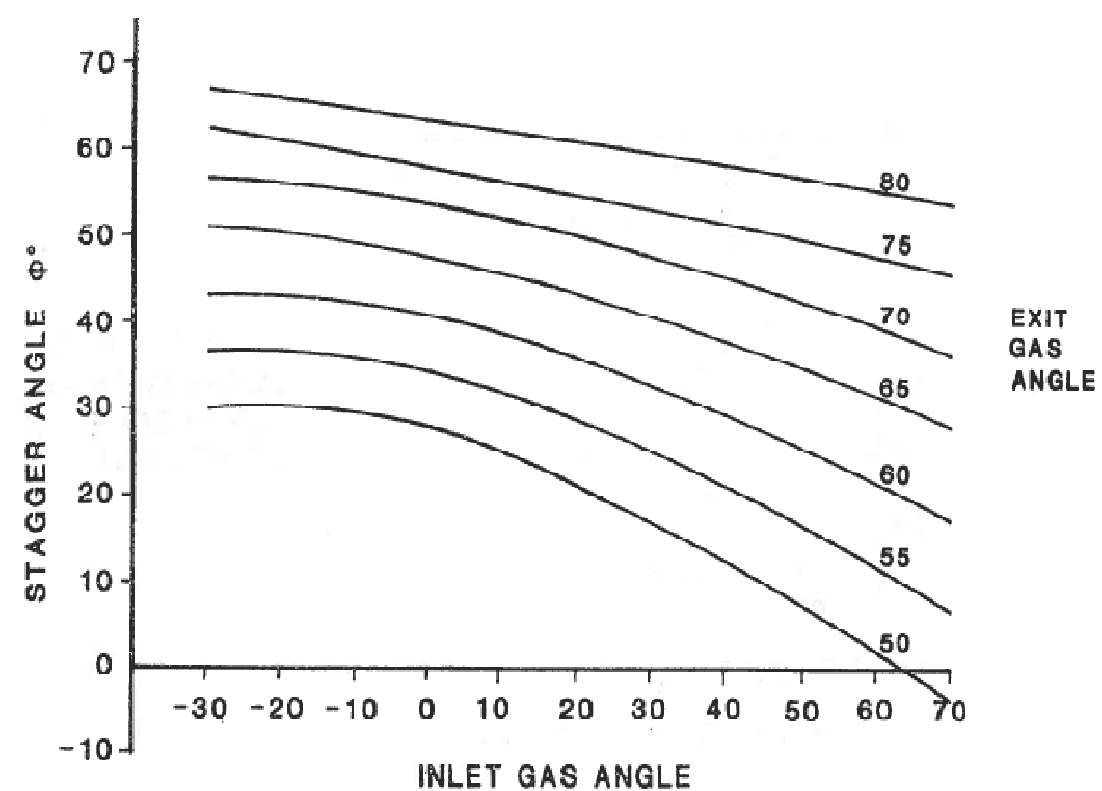

Fig. 6a Kacker \& Okapuu stagger prediction for a typical turbine blade section [7].

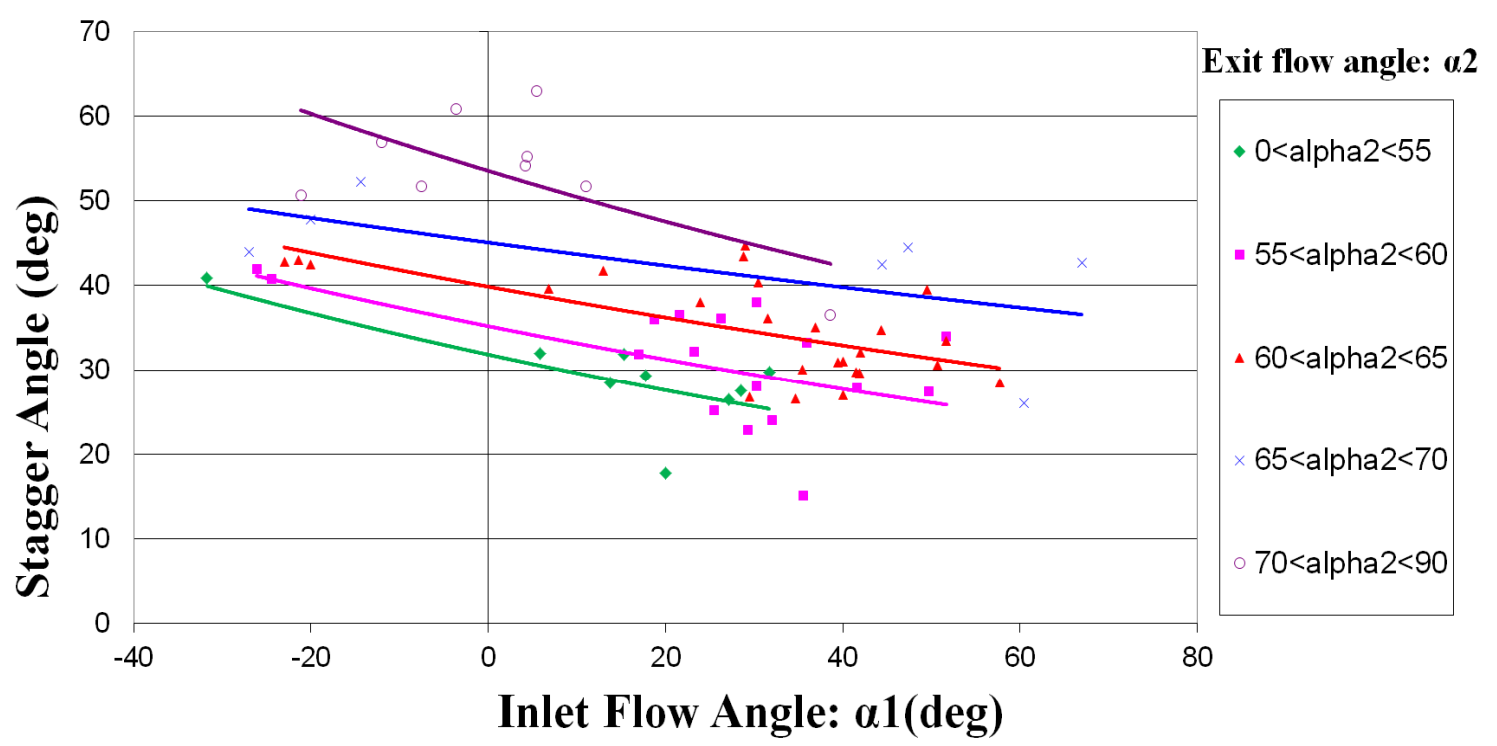

Fig. 6b RAF-3D stagger prediction for HPT blade mid-section.

experience and in-house design best practices for UT have been determined based on the airfoil exit Mach number (see Fig. 1).

\subsection{Hub and Tip Sections Parameter Extrapolation}

Up to this point, the details of mid-section parameters in RAF-3D have been discussed. However as mentioned before, the meanline cannot be used as accurately when it comes to hub and tip parameter prediction due to the free vortex assumptions made in the meanline calculations. Hub and tip sections parameters prediction can be categorized into three groups: parameters that have been assumed as constant (discussed previously), parameters that are scaled using an existing final design airfoil as baseline, and parameters that have been predicted using correlations found from the database. Meridional chord, LED and TET for hub and tip sections are predicted by scaling an existing airfoil as the baseline, using the relationship between the mid-section and 
that of the hub or tip. Below is RAF-3D formulation for calculating meridional chord for hub and tip sections. The hub meridional chord and the tip meridional chord, respectively, are defined as:

Hub meridional chord $\left(\mathrm{B}_{\mathrm{m}}\right)$ :

$$
\left(\text { hub ratio }{ }_{B m}\right)=\left[\frac{\left(B_{h u b}\right)}{\left(B m_{\text {mid }}\right)}\right]_{\text {baseline airfoil }}
$$

$\left(B m_{h u b}\right)_{R A F \text { concept design }}$

$$
=(\text { hub ratio } B m) *\left(B_{\text {mid }}\right)_{R A F}
$$

Tip meridional chord $\left(\mathrm{B}_{\mathrm{m}}\right)$ :

$$
\begin{aligned}
& \left(\text { tip ratio }_{B m}\right)=\left[\frac{\left(B m_{\text {tip }}\right)}{\left(B m_{\text {mid }}\right)}\right]_{\text {baseline airfoil }} \\
& \left(\text { Bm }_{\text {tip }}\right)_{R A F \text { concept design }} \\
& =\left(\text { tip ratio }_{B m}\right) *\left(B m_{\text {mid }}\right)_{R A F}
\end{aligned}
$$

LED and TET at hub and tip sections are also calculated similarly. Furthermore, a minimum allowable TET value is imposed to ensure manufacturability of the airfoil trailing edge. Leading and TEMAs for hub and tip sections are calculated in a similar manner to that of the mid-section with the difference that inlet and exit flow angles for hub and tip are not read directly from the meanline. Inlet and exit flow angles for hub and tip are calculated through correlations with respect to mid inlet and exit flow angles found through linear regression of the data in the RAF-3D database. P\&WC designed airfoils data were gathered and were carefully segregated in appropriate groups in order to pinpoint any existing trends. Correlations relating mid section inlet and exit flow angles to that at hub and tip sections are shown below:

$$
\begin{aligned}
& \text { (Inlet flow angle }{ }_{\text {hub }} \text { ) } \\
& =a *\left(\text { Inlet flow angle } \text { mid }_{\text {mid }}\right)+b
\end{aligned}
$$

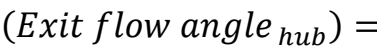

$$
\begin{aligned}
& c *\left(\text { Exit flow }_{\text {angle }} \text { mid }\right)+d \\
& \text { (Inlet flow angle tip) } \\
& =e *\left(\text { Inlet flow angle } \text { mid }_{\text {mid }}\right)+f \\
& \text { (Exit flow angle tip) } \\
& =g *\left(\text { Exit flow }_{\text {angle }} \text { mid }\right)+h
\end{aligned}
$$

where "a"-"h" are constants derived from P\&WC airfoil database, and therefore proprietary.

Having predicted the inlet and exit flow angles at the hub and tip, and assuming incidence and deviation angles as discussed earlier, hub and tip LEMA's and TEMA's can be calculated. RAF-3D predicts hub and tip sections' stagger angle and throat opening similar to the approach used for inlet and exit flow angles. Refer to Table 1 for a summary of the parameters used to parameterize the airfoil section CAD model and a brief description of the source of the values assigned to each parameter.

Finally, a 2D airfoil section CAD model was developed in order to visually inspect the outcome of RAF-3D parameter prediction. This $2 \mathrm{D}$ section model was used to generate a 3D airfoil by CG (Center of Gravity) stacking the 2D hub, mid and tip sections and then sweeping a surface from hub to tip.

A MATLAB program has been developed that automates the communication amongst TAML output, P\&WC airfoil database, 3D parameterized CAD model and in-house best practices, correlations and calculations that have been developed to date. The program generates a 3D airfoil shape that will be used for pre-detailed structural and vibration analyses as well as aerodynamic evaluation. A GUI is also being developed to improve usability.

\section{CFD Methodology}

The RAF-3D methodology has been validated from an aerodynamics perspective by performing CFD analyses. Steady-state turbine flowfields were predicted using the 3-D, RANS (Reynolds-Averaged Navier-Stokes) code described both by Ni [8] and Davis, et al. [9]. Numerical closure for turbulent flow is obtained via the $\mathrm{k}-\omega$ turbulence model due to Wilcox [10]. An O-H grid topology was employed for all simulations, and approximately 550,000 grid points per passage were used for three-dimensional simulations. The viscous-grid provides near-surface values of $y+$ less than 1 overall no-slip boundaries and gives approximately 7 grid points per momentum 


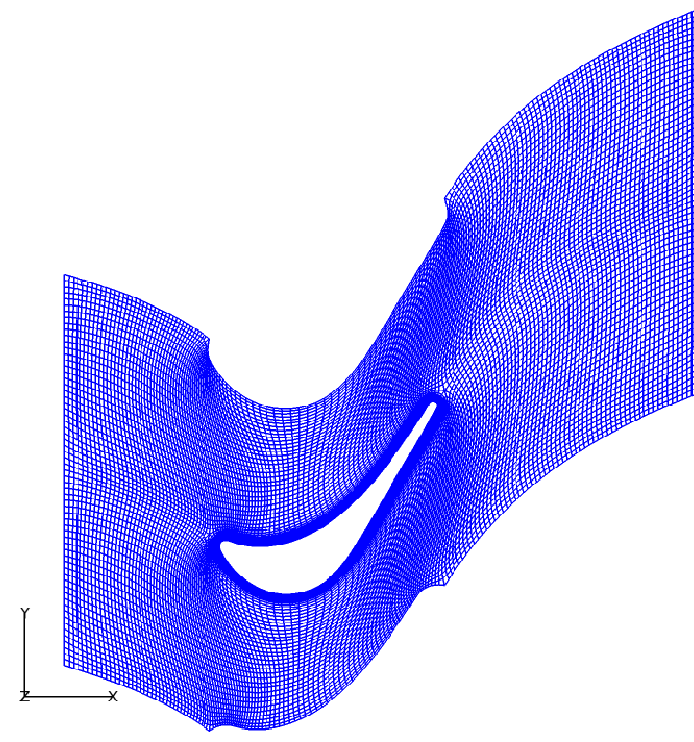

Fig. 7 O-H grid for turbine blade.

thickness in airfoil and endwall boundary layers. All walls are adiabatic and rotational. Fig. 7 shows an example of the airfoil O-H mesh.

For the CFD steady-state stage analysis, the vane and blade sectors of each stage are coupled by a mixing plane. All simulations were performed at engine representative conditions for these high-pressure transonic turbine stages. The mainstream inlet boundary conditions were provided from the combustor exit while the mainstream exit boundary conditions were provided from a multi-stage CFD simulation that includes the downstream stage. The mainstream inlet boundary conditions are specified as circumferentially averaged radial profiles of absolute total pressure, absolute total temperature and absolute flow angles while the mainstream exit boundary condition is specified as a circumferentially averaged radial profile of static pressure. The latter boundary condition accounts for the downstream stage effect. The term absolutely corresponds to stationary frame of reference.

\section{Results}

Three previously designed P\&WC uncooled HPT blades were selected to test the RAF-3D approach. These test cases will herein be referred to as test cases I, II and III. See Table 2. For each test case,

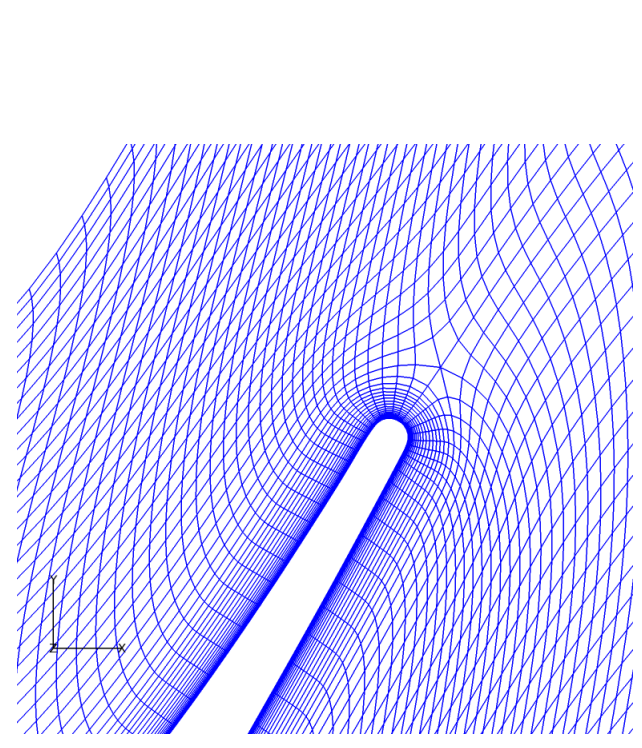

a TAML output was used in parallel with the airfoil database, assumptions, correlations, and calculations described previously to generate the RAF-3D concept airfoil shapes.

It must be noted that the following test cases assume a "redesign" of the high pressure turbine blade only, where the upstream high pressure turbine vane has not changed (a "redesign" in this context means test cases were chosen to see what "a design" of the blade only, in an uncooled CT environment, would look like compared to the actual ones that were actually designed). As the concept HPT blade and the final design HPT blade have the same HPT vane upstream, it is necessary to ensure that RAF-3D airfoil results in the same HPT stage reaction. The stage reaction requirement (a meanline input) was verified by performing Euler CFD and restagger was applied to the RAF-3D airfoil where necessary. The concept airfoils' stage reaction was matched to the respective final design airfoil within $0.25 \%$.

An O-H mesh, with identical meshing parameters to that of the final design airfoil, was generated. Viscous CFD analysis was performed at the aerodynamic design point which was $35,000 \mathrm{ft}$ max cruise for test case I and sea level take-off for test cases II and III. For each case, viscous CFD analyses were performed 
Table 2 RAF-3D test cases.

\begin{tabular}{lll}
\hline Case I & Case II & Case III \\
\hline Turboprop & Turboshaft & Turbofan \\
PT6 & PW200 & PW600 \\
\hline
\end{tabular}

for the RAF-3D airfoils and the respective final design airfoils using identical boundary conditions, upstream and downstream airfoils.

In the following Figs. 8-10, the scales of the Mach distribution have been eliminated in order to comply with $\mathrm{P} \& W C$ 's intellectual properties requirements. However, the absolute level of Mach numbers is unimportant, as identical scales have been used to generate both the final design and RAF-3D generated airfoil's Mach distribution, so it is the comparison of the two designs' Mach plots that are important. Note that the axial chords of airfoil mid-sections may not appear identical (the only section meant to be held constant at the meanline value); this is due to either scaling or axial shifting of the plots and not intended to show a change.

Fig. 8, test case I, shows a comparison of final design sections (red-obtained at the end of detailed design) and RAF-3D concept airfoil (black), pressure distribution, defined as the ratio of the static and total pressure $(\mathrm{Ps} / \mathrm{Pt})$, on airfoil surface and relative Mach contours at $5 \%, 50 \%$ and $95 \%$ span.

Fig. 9, test case II, shows a comparison of final design sections (red-obtained at the end of detailed design) and RAF-3D concept airfoil (black), pressure distribution on airfoil and relative Mach contours at $5 \%, 50 \%$ and $95 \%$ span.

Fig. 10, test case III, shows a comparison of final design sections (red-obtained from at the end of detailed design) and RAF-3D concept airfoil (black), pressure distribution on airfoil and relative Mach contours at $5 \%, 50 \%$ and $95 \%$ span.

From these figures, it can be seen that the airfoil shape at mid-section closely resembles the final design airfoil section. Furthermore, as seen in Figs. $8-10$, the airfoil sections created through the RAF-3D approach do not have any sudden curvature changes.
This results in smooth 3D airfoil shapes.

Viscous CFD results have also been used to compare the overall stage efficiencies of RAF-3D generated airfoils with the final design airfoils. Table 3 is a summary of the results.

As seen in Table 3, the largest stage efficiency penalty between the final design airfoil and the preliminary airfoil created through the RAF-3D design system is $0.7 \%$.

This delta efficiency is acceptable, at this stage in the design process, for a first pass airfoil generated from meanline information. A look at the Mach distribution of RAF-3D concept airfoil reveals opportunities to decrease this efficiency penalty.

As explained before, the above test cases focus on an HPT blade redesign only, rather than an HPT stage redesign. In order to further test the accuracy of RAF-3D approach, test case I has been repeated where a preliminary two-section 3D design of an HPT vane has been generated using the same TAML file and process used to predict the RAF-3D HPT blade. This HPT vane has been created in order to show the quality of the blade design when its final upstream vane is not known beforehand, as was the situation previously. This new HPT vane was used to size the RAF-3D HPT blade throat. Using Euler CFD, the concept vane and blade were re-staggered to achieve the flow and reaction from the meanline. Once this was achieved viscous CFD was performed by incorporating the updated HPT blade from RAF-3D process and the final design vane upstream to more accurately compare losses and efficiencies. The stage efficiency difference increased by only $0.1 \%(-0.58 \%$ to $-0.68 \%)$. This is confirmation that despite the preliminary nature of this airfoil design process, the delta efficiencies observed are small when compared to that of the detailed design airfoil. 

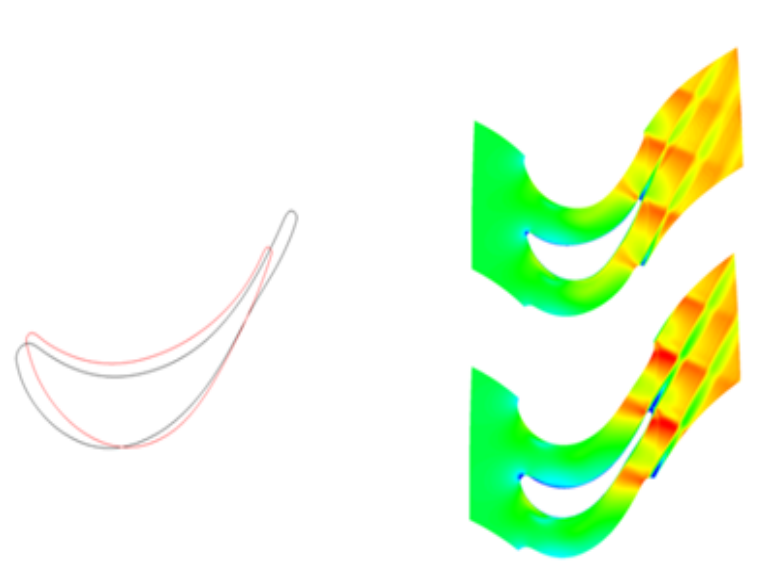

Airfoil Hub

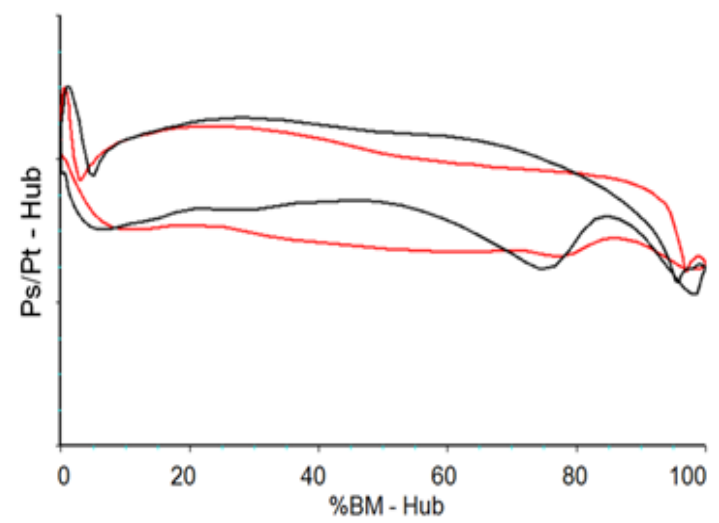

Airfoil Mid
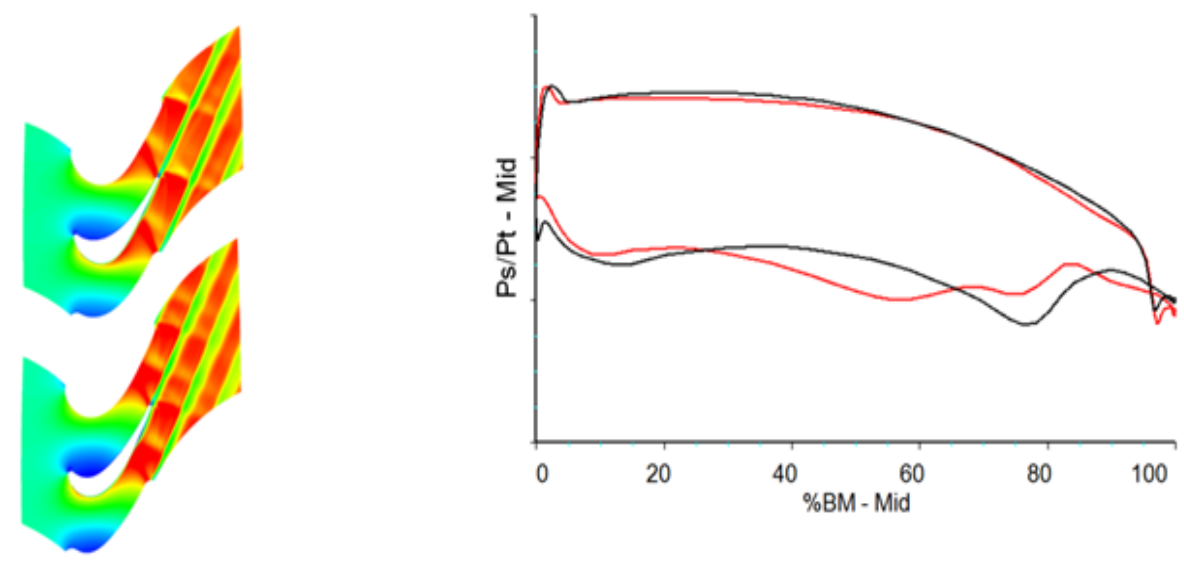

Airfoil Tip
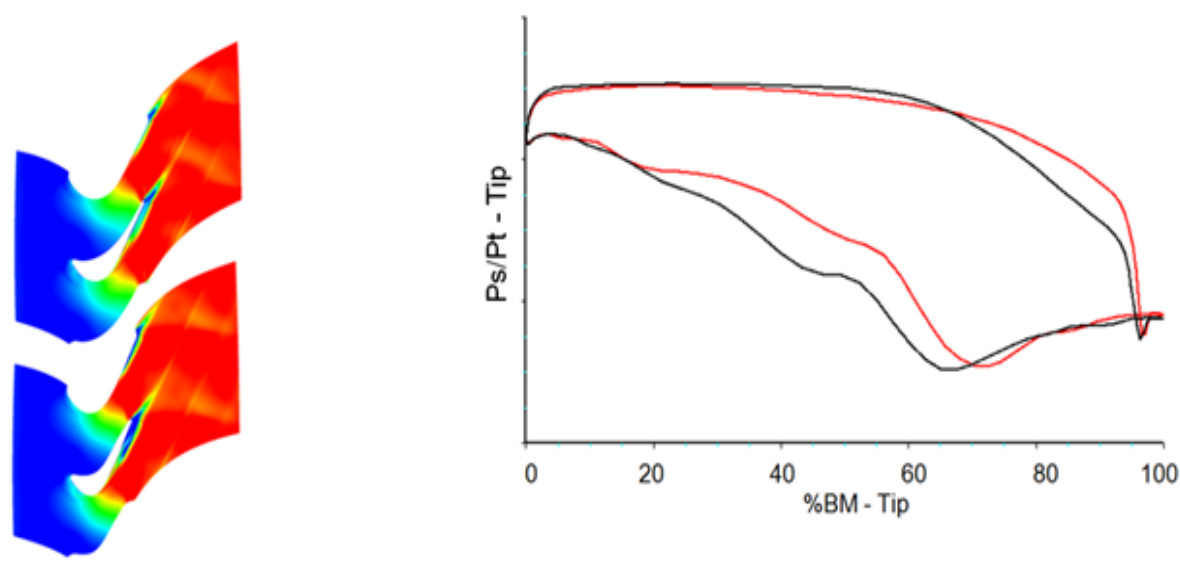

Fig. 8 Test Case I.

Left: airfoil section comparison of final design (red) and RAF-3D concept (black); Middle: relative Mach number comparison of final design (top) and RAF-3D Concept (bottom); Right: Ps/Pt comparison of final design (red) and RAF-3D concept (black). 

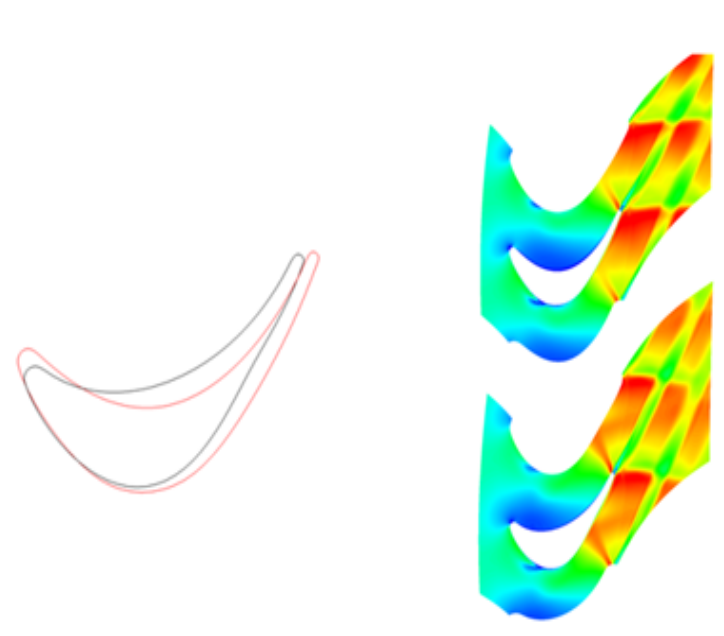

Airfoil Hub

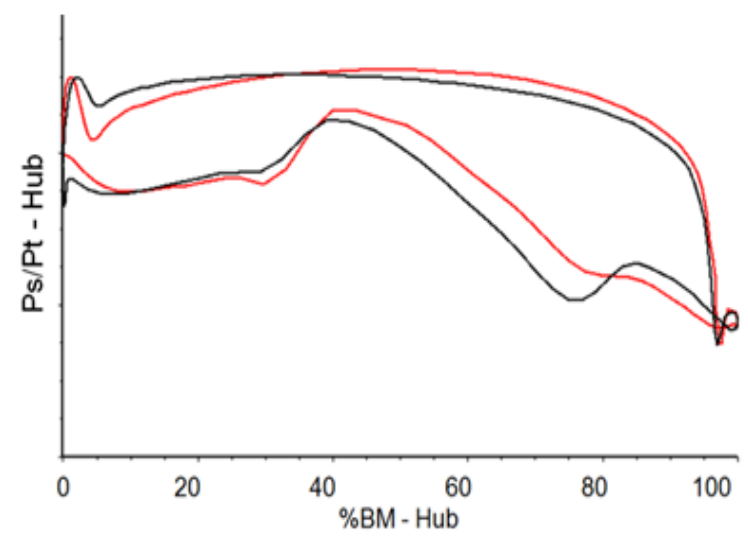

Airfoil Mid
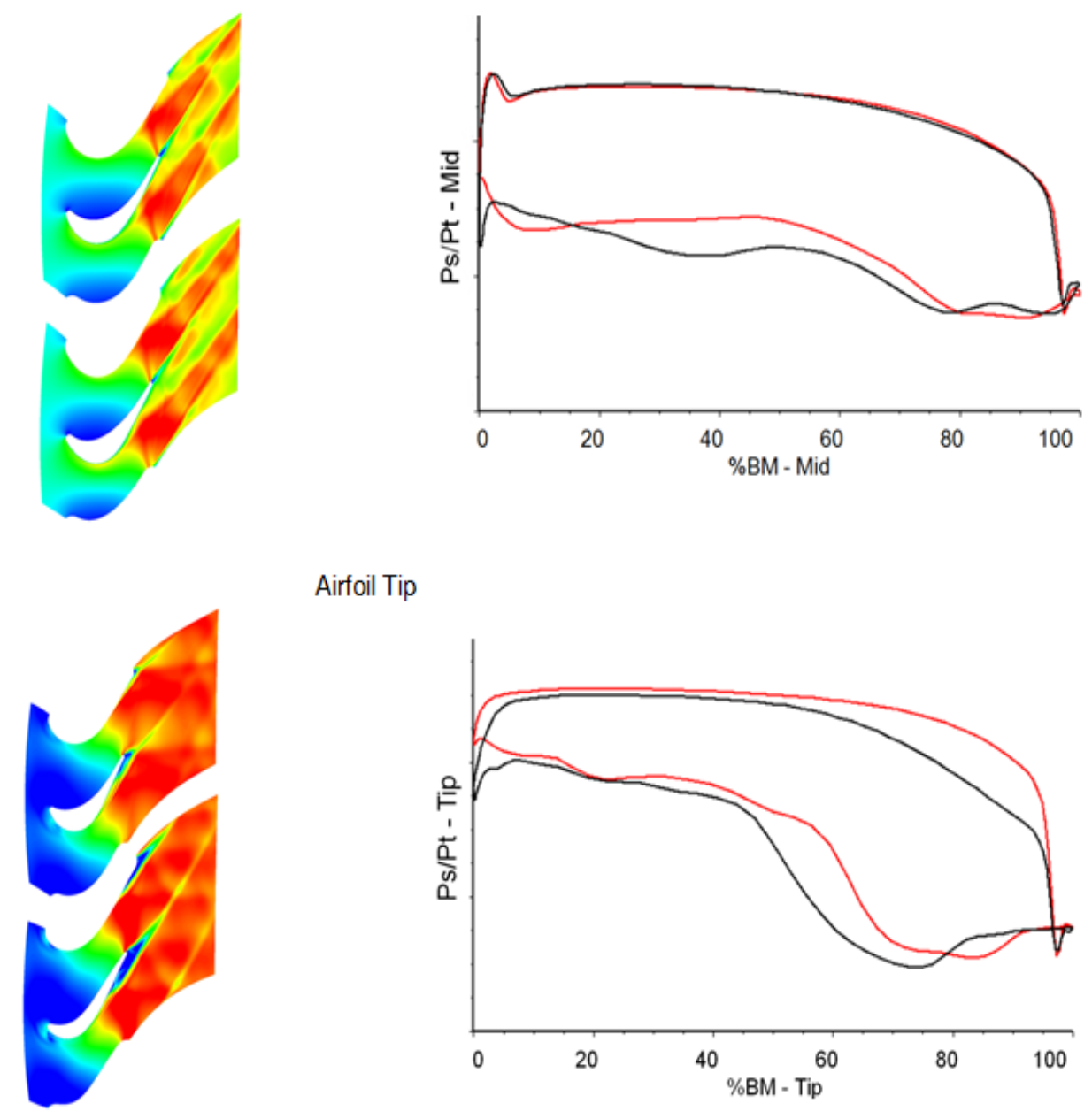

Airfoil Tip
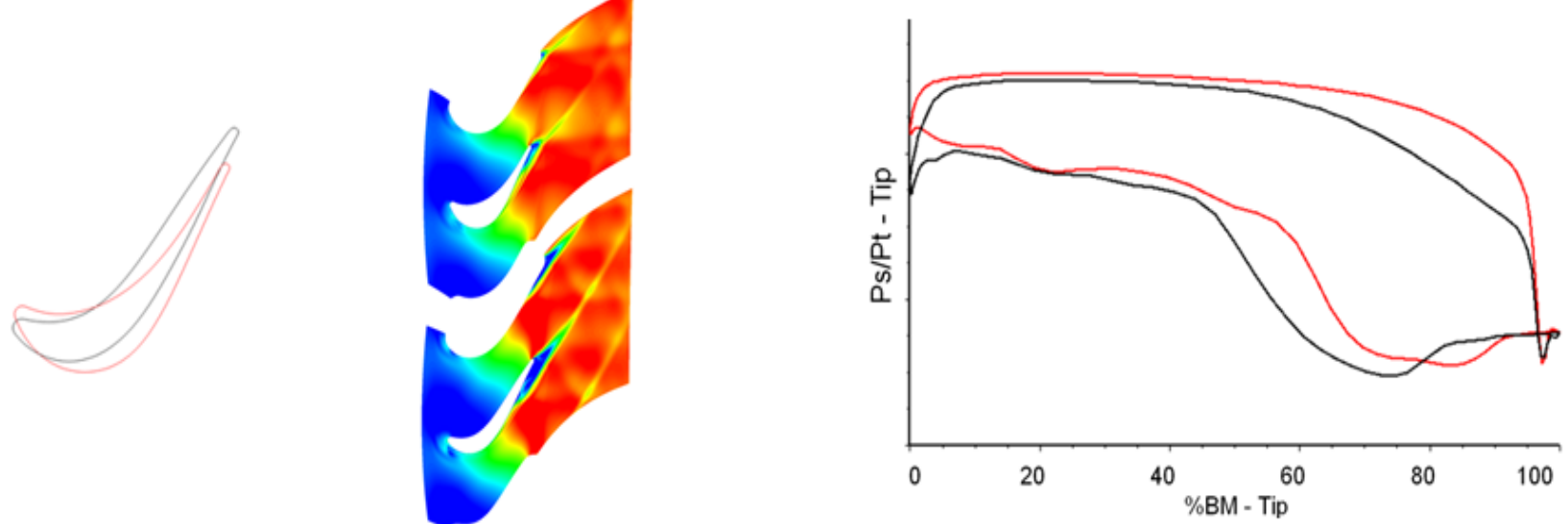

Fig. 9 Test Case II.

Left: airfoil section comparison of final design (red) and RAF-3D concept (black);

Middle: relative Mach number comparison of final design (top) and RAF-3D concept (bottom);

Right: Ps/Pt comparison of final design (red) and RAF-3D concept (black). 

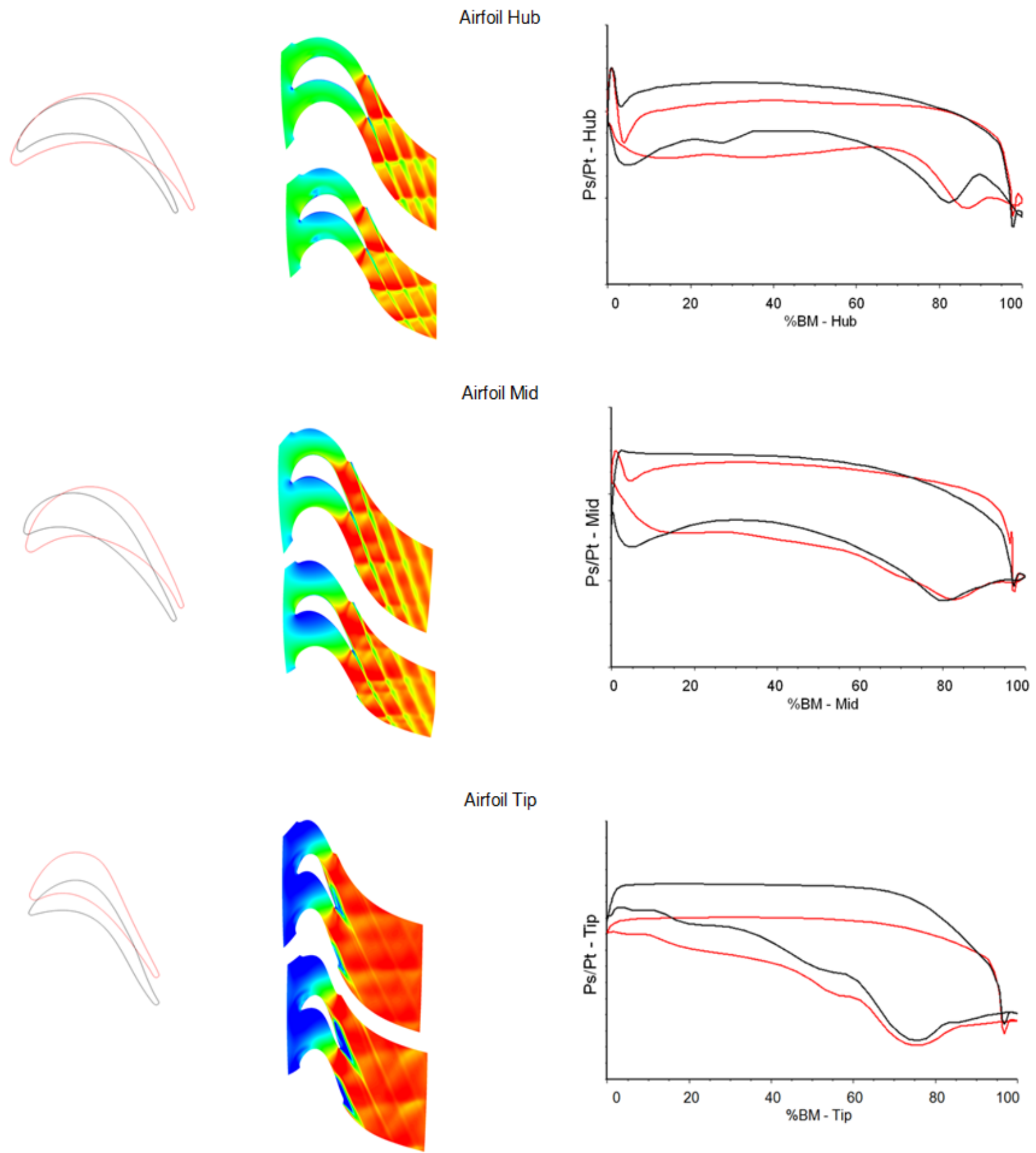

Airfoil Tip

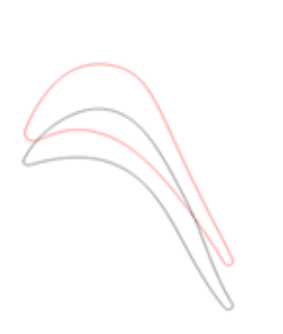

Fig. 10 Test Case III.

Left: airfoil section comparison of final design (red) and RAF-3D concept (black);

Middle: relative Mach number comparison of final design (top) and RAF-3D concept (bottom);

Right: Ps/Pt comparison of final design (red) and RAF-3D concept (black).

Table 3 Cases I, II and III HPT stage efficiency comparison: RAF-3D concept blade vs. final design.

\begin{tabular}{lll}
\hline Delta HPT stage efficiency $(\% \mathrm{pts})$ & & \\
\hline Case I & Case II & Case III \\
-0.58 & -0.39 & -0.70 \\
\hline
\end{tabular}




\section{Conclusion}

RAF-3D uses TAML, a database of previously designed P\&WC airfoils, in-house design best practices and an existing airfoil as baseline to generate a pre-detailed 3D airfoil shape, consisting of three design sections. First, the mid sections' parameters are updated using the data from the meanline. Next, hub and tip section parameters are predicted using correlations created from the RAF-3D airfoil database and baseline airfoil information. Once all parameters are read, predicted and/or calculated, a 3D CAD model is updated, and the airfoil shape is generated. The process described above has been fully automated through a Matlab code, and a GUI is being developed to improve usability.

RAF-3D approach has been validated by performing CFD analyses on three test cases from already existing $\mathrm{P} \& \mathrm{WC}$ airfoils using an in-house 3D RANS code. Viscous CFD analysis, with identical boundary conditions, upstream and downstream airfoils, was performed for both sets of airfoils (RAF-3D airfoils and the respective final design airfoils). The largest stage efficiency penalty for concept airfoils was $0.7 \%$. Considering the fact that final design airfoils result from weeks of fine tuning the airfoil shape compared to the pre-detailed nature of RAF-3D generated airfoils, this delta efficiency is deemed acceptable at this stage in the design process.

The main objective of this work was to reduce the time at which to arrive at the level of quality of the airfoils described earlier. RAF-3D automates the manual process of defining the first pass $3 \mathrm{D}$ airfoil from 1D TAML. In order to accurately assess the time savings achieved with RAF-3D, the time required to arrive at cycle zero airfoil during detailed design for test case III (the most recent engine design) was compared to a comparable airfoil generated using RAF-3D. Using the conventional method, turbine aerodynamics spent 8 business days generating the first cycle 3D airfoil shape. RAF-3D reduced the time required to 6 hours (which includes time to do all the background work e.g. choosing the appropriate baseline airfoil). This translates to a time saving factor of 10 .

In the case of the un-cooled HPT blade (the prime focus of this paper) the overall risk to an engine program will be greatly reduced because the need, for example, to "cut-back" a portion of the blade tip to reduce dynamic stresses in development, will be eliminated. This is due to the fact that a more detailed analysis was done in the pre-detailed design stage by creating a "90\%" aero airfoil which would then be analyzed at a very early stage to highlight any problem areas.

Due to its design requirements, RAF-3D is currently focusing on the uncooled HPT blade. However the vision is to broaden the application of RAF-3D for other P\&WC airfoil types such as cooled high pressure turbine blades and fan and power turbine blades.

\section{Acknowledgements}

The authors would like to thank Benoit Blondin, Bruno Chatelois, and Daniel Lecuyer of P\&WC for their support and contribution towards the development of the 3D CAD model.

\section{References}

[1] Panchenko, V., Patel, K., Moustapha, H., Dowhan, M. J., Mah, S., and Hall, D. 2002. Preliminary Multi-disciplinary Optimization in Turbomachinery Design. NATO RTA, 21.

[2] Ryan, R., Blair, J., Townsend, J., and Verderaime, V. 1996. Working on the Boundaries: Philosophies and Practices of the Design Process. NASA Technical report No. 19960049664.

[3] Otto, D., and Wenzel, H. 2010. Simplification and Automated Modification of Existing Insight-Processes. Rolls Royce Deutschland Ltd \& Co KG.

[4] Anders, J. M., Haarmeyer, J., and Heukenkamp, H. 2002. A Parametric Blade Design System (Part I + II). VKI Lecture 1.

[5] Brophy, F., Mah, S., and Turcotte, J. 2009. "Preliminary Multidisciplinary Optimization (PMDO) an Example at 
Engine Level.” NATO RTA, AVT-167, 14.

[6] Moustapha, H., Baines, N., Japikse, D., and Zeleski, M. 2003. Axial and Radial Turbines. Concepts NREC Book.

[7] Kacker, S. C., and Okapuu, U. 1982. "Mean Line Prediction Method for Axial Flow Turbine Efficiency." Journal of Engineering for Power 104 (1): 111-9.

[8] Ni, R. H. 1999. “Advanced Modeling Techniques for
New Commercial Engines." Presented at XIV ISABE Conference, Florence, Italy, 5-10 September.

[9] Davis, R. L., Shang, T., Buteau, J., and Ni, R. H. 1996. "Prediction of 3-D Unsteady Flow in Multi-stage Turbomachinery Using an Implicit Dual Time-Step Approach.” AIAA Paper No. 96-2565.

[10] Wilcox, D. C. 1998. Turbulence Modeling for CFD, 2nd ed. La Canada, CA: DCW Industries, Inc.. 